\title{
Effects of extracts from Cordyceps sinensis on MI muscarinic acetylcholine receptor in vitro and in vivo
}

This article was published in the following Dove Press journal:

Journal of Receptor, Ligand and Channel Research

II August 2010

Number of times this article has been viewed

\author{
Tomohiro Chiba' \\ Marina Yamada' \\ Kosuke Torii ${ }^{2}$ \\ Masataka Suzuki' \\ Jumpei Sasabe' \\ Minoru Ito ${ }^{2}$ \\ Kenzo Terashita' \\ Sadakazu Aiso' \\ 'Department of Anatomy, Keio \\ University, School of Medicine, Tokyo, \\ Japan; ${ }^{2}$ Department of Research and \\ Development, Noevir Co. Ltd., Tokyo, \\ Japan
}

Correspondence: Tomohiro Chiba 35 Shinanomachi, Shinjuku-ku, Tokyo 160-8582, Japan

Tel +8I-3-5363-3745

Fax +8I-3-5360-1524

Email chibat@sc.itc.keio.ac.jp

\begin{abstract}
Cholinergic dysfunction is implicated in the pathogenesis of memory impairment related to Alzheimer's disease (AD). Accordingly, regulation of M1 muscarinic acetylcholine receptor (M1 $\mathrm{mAChR}$ ) has been one of the major targets in the development of novel drugs for $\mathrm{AD}$. Utilizing an in vitro system for evaluation of the M1 $\mathrm{mAChR}$, we have recently identified that extracts from Cordyceps sinensis (CS) promote M1 mAChR function. In this study, we examined the effect of pretreatment with several types of CS extracts in F11 neurohybrid cells on ERK phosphorylation induced by a muscarinic agonist, carbachol (CCh). A mixed extract of a hot water extract and an ethanol extract from CS augmented ERK phosphorylation by CCh presumably through upregulation of M1 mAChR function. We further examined the effect of oral administration of CS extracts on memory impairment induced by a muscarinic antagonist scopolamine in mice, finding that CS extracts ameliorated scopolamine-induced amnesia in vivo, consistent with the in vitro data. Thus CS extracts may contribute to the prevention of memory impairment related to AD.
\end{abstract}

Keywords: Cordyceps sinensis, Alzheimer's disease, m1-muscarinic acetylcholine receptor, memory impairment

Cholinergic dysfunction has been implicated in the pathogenesis of Alzheimer's disease (AD). Progressive cholinergic denervation in the cerebral cortex as well as decreased levels of acetylcholine (ACh) and choline acetyltransferase (ChAT) has been reported to be associated with AD-relevant cognitive impairment. ${ }^{1,2}$ Similarly, acetylcholinesterase (AChE) inhibitors such as Donepezil, which increase ACh concentrations around the synaptic cleft by inhibiting ACh degradation, moderately improve cognitive function in AD patients. ${ }^{3-6}$ Given that augmentation of cholinergic neurotransmission contributes to alleviation of memory impairment related to $A D$, stimulation or activation of ACh receptors (AChRs) are also deemed to be promising targets for the development of a novel AD therapy.

There are two types of AChRs: muscarinic and nicotinic AChRs. The former muscarinic $\mathrm{AChRs}(\mathrm{mAChRs})$ are $\mathrm{G}$ protein-coupled receptors activating intracellular second messengers and the latter nicotinic AChRs are ligand-gated ion channels. ${ }^{7-9}$ Among the AChRs, M1 mAChR (M1 mAChR) is likely to be that involved in AD pathogenesis for several reasons. ${ }^{10}$ (i) A specific M1 mAChR agonist improved hippocampal plasticity by potentiating $N$-methyl-D-aspartate receptor activity, ${ }^{11}$ (ii) M1 mAChR-deficient mice showed severe memory impairment, ${ }^{12}$ and (iii) M1 mAChR agonists attenuated memory impairment in an AD model. ${ }^{13}$ In our previous study, we found that the Janus kinase 2 (JAK2)/signal transducer and activator of transcription 3 (STAT3) signaling

submit your manuscript $\mid$ www.dovepress.com 
axis in hippocampal neurons is inactivated by Alzheimer's amyloid- $\beta$ (A $\beta$ ) peptide, which results in desensitization of M1 mAChR. ${ }^{14,15}$ We also reported that a novel neuroprotective peptide named colivelin promoted M1 mAChR function by activating the JAK2/STAT3 axis in hippocampal neurons and ameliorated memory impairment in multiple AD models in vivo. ${ }^{14,15}$

Phosphorylation of extracellular-signal regulated kinase (ERK) through M1 mAChR is reported to play important roles not only in the induction of long-term depression in the rat hippocampus, ${ }^{16}$ but also in the neuronal differentiation in hippocampal pyramidal neurons, ${ }^{17}$ suggesting that the M1 mAChR-ERK signaling pathway in hippocampal neurons is likely to regulate memory in vivo. Utilizing a muscarinic agonist carbachol $(\mathrm{CCh})$ as a ligand for $\mathrm{M} 1 \mathrm{mAChR}$, the function of M1 mAChR can be evaluated in a simple in vitro system based on the M1 mAChR-ERK signaling pathway. In neuronal cell lines such as PC12 and F11 cells, $\mathrm{CCh}$ treatment induces rapid ERK phosphorylation through M1 mAChR. ${ }^{14,18}$

Drugs for AD should be safe with few side effects because they will be used for an extended period of time. To obtain ingredients that promote M1 mAChR function, we performed a functional screening of natural products that have been used in humans for centuries and have been proven to be safe using the CCh-induced ERK phosphorylation system in vitro (data not shown). Finally, we found that pretreatment of F11 cells with extracts from Cordyceps sinensis (CS) significantly augments CCh-induced ERK phosphorylation.

$\mathrm{CS}$ is a fungus parasitic to Hepialidae larvae and has been used as a traditional medicine in China. In many studies it has been shown that CS possesses various biological activities that support human homeostasis such as antitumor, ${ }^{19,20}$ antioxidant, ${ }^{21,22}$ immunomodulatory, ${ }^{23-25}$ hypoglycemic, ${ }^{26,27}$ vasorelaxant activities, ${ }^{28}$ and antidepressant activity. ${ }^{29}$ A methanol extract from Cordyceps ophioglossoides, a similar parasitic mushroom, was reported to scavenge the reactive oxygen species (ROS) generated by $\mathrm{A} \beta$ peptides. ${ }^{30} \mathrm{~A}$ hot water extract from CS was also reported to elicit antiaging effects, including improvement of memory function, from mice aged by D-galactose through upregulation of ROS scavenging activities. ${ }^{31}$ The effect of CS extracts on cholinergic neurotransmission, however, remains to be addressed.

In the present study, we evaluated the effect of CS extracts on $\mathrm{M} 1 \mathrm{mAChR}$ function in vitro and also reported the in vivo effect of CS extracts on an anti-cholinergic drug-induced memory impairment model.

\section{Material and methods Materials}

A rabbit polyclonal antibody against phospho-extracellular signal-regulated kinase $1 / 2$ (p-ERK1/2) ( $\mathrm{Thr}^{202} / \mathrm{Tyr}^{204}$ ) was obtained from Cell Signaling Technology (Beverly, MA). A rabbit polyclonal antibody against total-ERK1/2 (t-ERK1/2) was obtained from Santa Cruz Biotechnology (Santa Cruz, CA). Carbamylcholine chloride (carbachol, $\mathrm{CCh}$ ) and scopolamine hydrobromide were obtained from Sigma-Aldrich (St. Louis, MO). Extracts from Cordyceps sinensis (CS) were provided by Noevir Co. Ltd (Tokyo, Japan). Pirenzepine (PIR) and dicyclomine (DCM) were provided by Sigma-Aldrich. Other reagents described here are commercially available.

\section{Preparation of CS extracts}

A hot water extract of CS (HWCS) was prepared by boiling $10 \mathrm{~g}$ of $\mathrm{CS}$ in $200 \mathrm{~g}$ of water at approximately $100^{\circ} \mathrm{C}$ for 90 minutes, followed by filtration and freeze-drying (yield: approximately 30\%). ${ }^{29}$ An ethanol (EtOH) extract of CS (ECS) was obtained from residues of HWCS in $100 \mathrm{~g}$ of $\mathrm{EtOH}(>99.5 \%)$ at approximately $80^{\circ} \mathrm{C}$ for 60 minutes, followed by filtration and freeze-drying (yield: approximately $8 \%$ ). A mixed extract of HWCS and ECS $(\mathrm{HW}+\mathrm{E})$ was prepared by filtrating and freeze-drying the mixture of each extract obtained from $10 \mathrm{~g}$ of CS. All extracts were dissolved in sterile deionized distilled water for treatments. Quality of the extracts was carefully controlled by using CS originating from a restricted area of Tibet. Preparation of the extracts was repeated at least three times and we observed essentially the same results for each of the extracts.

\section{Cell culture and treatments}

F11 neurohybrid cells were grown in Ham's F12 medium containing 18\% FBS as described previously. ${ }^{14,32}$ For ERK phosphorylation assays, F11 (at $1.2 \times 10^{5}$ per well in a 6 -well plate, cultured in serum-free media for 24 hours) were incubated with indicated doses of CS extracts for 30 minutes. Cells were washed twice with serum-free media and were then treated with $5 \mu \mathrm{M}$ CCh for 5 minutes. ${ }^{14,18}$ Cells were harvested in a lysis buffer containing phosphatase inhibitors (50 mM Tris $\mathrm{HCl}$ [pH7.4], $150 \mathrm{mM} \mathrm{NaCl}, 1 \%$ Triton-X 100, Complete protease inhibitors [Roche Applied 
Science; Mannheim, Germany], 1 mM EDTA, phosphatase inhibitor cocktails 1 and 2 [Sigma-Aldrich]). Samples (20 $\mu \mathrm{g}$ protein/lane) were subjected to normal SDS-PAGE and were then blotted onto PVDF membranes. The membranes were soaked with appropriate primary antibodies (p-ERK1/2, 1:1000; t-ERK1/2, 1:3000) and then with HRP-labeled secondary antibodies (BioRad Laboratories; Hercules, CA). Immunoreactive bands were detected using ECL Western Blotting Detection Reagents (Amersham Bioscience; Uppsala, Sweden). Densitometric analyses were performed using ImageJ 1.42q (http://rsb.info.nih.gov/ij/ index.html).

\section{Animals and treatments}

This study was conducted in accordance with the Guidelines for the Care and Use of Laboratory Animals of KEIO University School of Medicine. All experimental procedures were approved by the Institutional Animal Experiment Committee at KEIO University.

Male CD-1 mice aged 8 weeks were purchased from Charles River Japan Inc. (Kanagawa, Japan), kept at least for one week in a specific pathogen-free animal facility $\left(23 \pm 1{ }^{\circ} \mathrm{C}, 50 \pm 5 \%\right.$ humidity), under a 12 hour light : dark cycle (07.00-19.00 hours). They were fed ad libitum with $\gamma$-ray-irradiated Picolab Rodent Diet 20 (PMI Feeds, St Louis, MO, USA) and sterilized deionized distilled water supplemented with sodium hypochlorite (5 ppm). Plastic cages (CLEA Japan, Tokyo, Japan) were autoclaved and ALPHA-dri bedding material (Shepherd Specialty Papers, Kalamazoo, MI, USA) was sterilized by heating at $80^{\circ} \mathrm{C}$ for 12 hours before use and changed once a week. Mice were handled by experienced researchers engaged in daily husbandry of the tested animals, in a quiet environment adjoining the room for housing. An open field test (OF) was performed as described previously to habituate the mice to the experimental conditions. ${ }^{33,34} \mathrm{~A}$ Y-maze test (YM) was performed as described. ${ }^{33,34}$ The apparatus for YM was made of gray plastic, with each arm $40 \mathrm{~cm}$ long, $12 \mathrm{~cm}$ high, $3 \mathrm{~cm}$ wide at the bottom, and $10 \mathrm{~cm}$ wide at the top. The three arms were connected at an angle of $120^{\circ}$. Mice were individually placed at the end of an arm and allowed to explore the maze freely for 8 minutes. Spontaneous alternation percentage (SA\%), defined as a ratio of the arm choices that differed from the previous two choices ("successful choices") to total choices during the run ("total entry minus two" because the first two entries could not be evaluated), was measured as an index of spatial working memory in YM. A passive avoidance test (PA) was performed as described. ${ }^{14,34}$ Briefly, mice were first confined in an illuminated chamber for 15 seconds and then allowed to enter an adjacent dark chamber. Soon after the mice entered the dark chamber, they were given an inescapable electric shock (0.3 mA, 3 seconds, once) through the floor grid. Each mouse was again tested in the apparatus 24 hours later. Entry latency was defined as time elapsed until the mouse entered into the dark chamber (maximum 300 seconds) was measured as an index of contextual memory in PA.

\section{Statistical analyses}

All values in the figures are shown as means \pm SEM. Statistical analysis was performed with one-way analysis of variance (ANOVA) in which the alpha value was set at 0.05 and was assessed, followed by a Tukey's post-hoc multiple comparison. All data were analyzed using Prism 5 (Ver.5.0b) software (GraphPad Software, Inc.; San Diego, CA).

\section{Results \\ Effects of CS extracts on CCh-induced ERK phosphorylation through MI $\mathrm{mAChR}$ in FII neurohybrid cells}

A muscarinic agonist $\mathrm{CCh}$ is reported to induce ERK phosphorylation in a dose-dependent fashion in neuronal cell lines such as PC12 pheochromocytoma cells and F11 neurohybrid cells..$^{14,18}$ To test if ERK phosphorylation induced by $\mathrm{CCh}$ requires specific activation of $\mathrm{M} 1 \mathrm{mAChR}$, we treated F11 cells with CCh together with pirenzepine (PIR) and dicyclomine (DCM), which are highly specific competitive antagonists for M1 mAChR (Figure 1A). ${ }^{14,35} \mathrm{CCh}$ induced a robust increase in ERK phosphorylation. PIR and DCM almost completely inhibited ERK phosphorylation induced by $\mathrm{CCh}$, suggesting that ERK phosphorylation by $\mathrm{CCh}$ in F11 cells is largely due to the stimulation of M1 mAChR.

To search for safe ingredients that promote $\mathrm{M} 1 \mathrm{mAChR}$ function, we pretreated F11 cells with a number of extracts from natural products and examined CCh-induced ERK phosphorylation by immunoblot analyses (data not shown). We finally found that extracts from CS significantly augment CCh-induced ERK phosphorylation. Considering that ingredients will differ according to the methods of extract preparation, we examined the effect of multiple types of CS extracts at $10 \mu \mathrm{g} / \mathrm{mL}$ on CCh-induced ERK phosphoryla- 
A

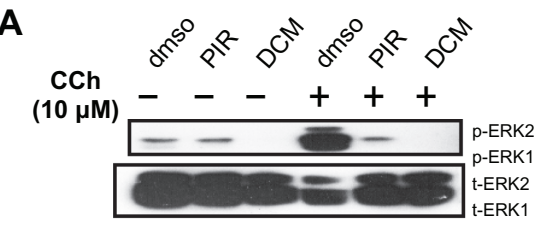

p-/t-ERK1 $0.07 \quad 0.08 \quad 0.01 \quad 0.350 .090 .02$

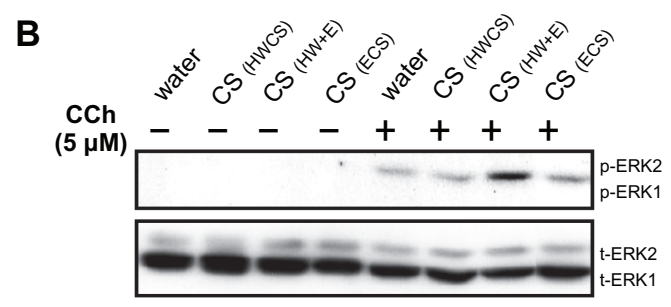

p-/t-ERK1 $0.01 \quad 0.00 \quad 0.010 .02 \quad 0.18 \quad 0.18 \quad 0.54 \quad 0.26$

C

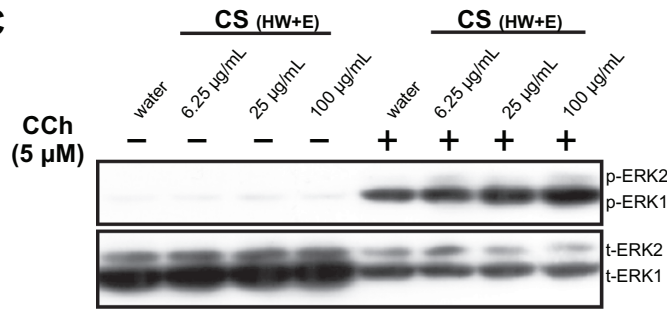

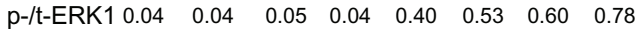



Figure I Effects of CS extracts on CCh-induced ERK phosphorylation in FII cells. A) Representative immunoblots of lysates $(20 \mu \mathrm{g} / \mathrm{lane})$ of cells treated with vehicle or $10 \mu \mathrm{MCCh}$ together with MI specific inhibitors, pirenzepine (PIR), and dicyclomine (DCM). FI I cells were treated with $10 \mu \mathrm{M} \mathrm{CCh}$ for 5 min together with dmso $(0.5 \%)$, PIR (I $\mu \mathrm{M})$, or DCM $(I \mu \mathrm{M})$. Immunoblot analyses were performed with antibodies against phospho-ERK (p-ERK) and total-ERK (t-ERK) (both antibodies recognize ERKI (42 kDa) and ERK2 (44 kDa)). Densitometrical ratios of P-ERKI to t-ERKI of the picture were indicated under the panel. B) Representative immunoblots of lysates $(20 \mu \mathrm{g} / \mathrm{lane})$ of cells treated with vehicle or $5 \mu \mathrm{M} \mathrm{CCh}$ together with pretreatments of multiple types of CS extracts. FII cells were first treated for 30 min with a hot water extract (HWCS), an ethanol extract (ECS), a mixed extract of HWCS and ECS (HW + E) of CS dissolved in sterile deionized distilled water at $10 \mu \mathrm{g} / \mathrm{mL}$. Then, the cells were treated with $5 \mu \mathrm{M} \mathrm{CCh}$ for $5 \mathrm{~min}$. Immunoblot analyses were similarly performed with antibodies against $\mathrm{p}$-ERK and $t$-ERK. Densitometrical ratios of p-ERKI to t-ERKI of the picture were indicated under the panel. C) Representative immunoblots of lysates $(20 \mu \mathrm{g} / \mathrm{lane})$ of cells similarly treated with vehicle (veh) or $5 \mu \mathrm{M} \mathrm{CCh}$ together with pretreatment of a mixed extract of HWCS and ECS (HW + E) at indicated doses $(6.25,25$, and $100 \mu \mathrm{g} / \mathrm{mL}$ ). Densitometrical ratios of p-ERKI to t-ERKI of the picture were indicated under the panel. D) Densitometry of three independent experiments or immunoblots of cells treated with or without a mixed CS extract $(\mathrm{HW}+\mathrm{E})$ at $100 \mu \mathrm{g} / \mathrm{mL}$. The densitometry of the ratio of $p^{-}$to t-ERK was calculated using Image J software. The data are shown as means \pm SEM. One-way ANOVA revealed a significant difference among the groups $\left(F_{(3,11)}=137.6 ; P<0.000 I\right)$. $* * P<0.01$ by a Tukey's post hoc test. tion in F11 cells (Figure 1B). Neither pretreatment with a hot water extract (HWCS) nor that with an ethanol extract from CS (ECS) affected ERK phosphorylation induced by CCh. In clear contrast, a mixed extract of HWCS and ECS $(\mathrm{HW}+\mathrm{E})$ significantly augmented ERK phosphorylation induced by $\mathrm{CCh}$. None of the CS extracts affected total ERK protein levels. We further observed a CS extract dosedependent increase in CCh-induced ERK phosphorylation (Figure 1C). A mixed extract (HW + E) of $100 \mu \mathrm{g} / \mathrm{mL}$ elicited the strongest effect on ERK phosphorylation.

To confirm the effect of a mixed extract $(\mathrm{HW}+\mathrm{E})$ on M1 mAChR, we repeated the experiments and performed densitometric analyses of the ratio of phosphorylated ERK to total ERK proteins (Figure 1D). Pretreatment with CS extracts $(\mathrm{HW}+\mathrm{E})$ at $100 \mu \mathrm{g} / \mathrm{mL}$ itself did not affect ERK phosphorylation, while pretreatment with CS extracts $(\mathrm{HW}+\mathrm{E})$ significantly augmented the rapid elevation of ERK phosphorylation levels induced by CCh treatment in F11 cells. CCh-induced ERK phosphorylation in F11 cells pretreated with CS extracts was approximately twice as high as that in F11 cells with vehicle pretreatment. The data indicated that a mixed extract upregulated ERK phosphorylation by $\mathrm{CCh}$ treatment by promoting $\mathrm{M} 1 \mathrm{mAChR}$ function.

\section{Effects of PIR on CS extracts-induced increase in ERK phosphorylation by $\mathrm{CCh}$ treatment in FII cells}

Next, we tried to characterize the effect of CS extracts on M1 mAChR function. To this end, we treated F11 cells with CS extracts $(\mathrm{HW}+\mathrm{E})$ together with or without PIR, a specific $\mathrm{M} 1$ antagonist for 30 minutes and then treated with $\mathrm{CCh}$ in the absence of PIR (Figure 2A). As a result, we observed a significant increase in CCh-induced ERK phosphorylation by CS extracts, as in Figure 1, regardless of pretreatment with PIR, suggesting that the effect of CS extracts on ERK phosphorylation induced by $\mathrm{CCh}$ is not due to direct binding of CS extracts to M1 mAChR.

We also examined the effect of PIR treatment simultaneously with $\mathrm{CCh}$ treatment to confirm that the increased ERK phosphorylation by CS extracts is truly dependent on M1 mAChR. Without PIR treatment, we observed a significant increase in CCh-induced ERK phosphorylation by pretreatment with $\mathrm{CS}$ extracts $(\mathrm{HW}+\mathrm{E})$ (Figure 2B). In contrast to the pretreatment of CS extracts and PIR, PIR almost completely suppressed CCh-induced ERK phosphorylation in both cells with and without pretreatment with CS extracts, suggesting that the increased ERK 
A

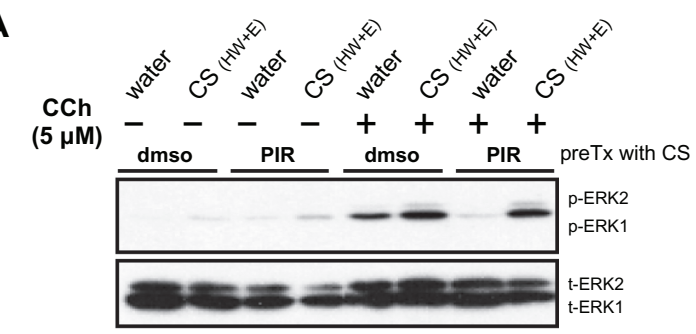

p-/t-ERK1 $\quad 0.01 \quad 0.02 \quad 0.02 \quad 0.06 \quad 0.18 \quad 0.29 \quad 0.03 \quad 0.28$



Figure 2 Effects of PIR on CS-induced increase in ERK phosphorylation by CCh in FII cells. A) Effects of the pretreatment with PIR (I $\mu \mathrm{M})$ on CS-induced increase in p-ERK by CCh. Representative immunoblots of lysates $(20 \mu g / l a n e)$ of cells treated with vehicle or $5 \mu \mathrm{M} \mathrm{CCh}$. FII cells were first pretreated with vehicle or CS extracts $(\mathrm{HW}+\mathrm{E}$ at $10 \mu \mathrm{g} / \mathrm{mL})$ in the presence or absence of PIR $(I \mu \mathrm{M})$, and they were then treated with or without $10 \mu \mathrm{M} \mathrm{CCh}$ for $5 \mathrm{~min}$. Densitometrical ratios of $\mathrm{p}$-ERK I to $t$-ERKI of the picture were indicated under the panel. B) Effects of PIR (I $\mu \mathrm{M})$ on CCh-induced p-ERK. Representative immunoblots of lysates $(20 \mu \mathrm{g} / \mathrm{lane})$ of cells treated with vehicle (veh) or $5 \mu \mathrm{M}$ CCh together with or without PIR (I $\mu \mathrm{M})$ FII cells were first treated for 30 min with CS extracts $(H W+E)$ at $10 \mu \mathrm{g} / \mathrm{mL}$. Cells were then treated with $5 \mu \mathrm{M} \mathrm{CCh}$ for 5 min together with dmso or PIR (I $\mu \mathrm{M})$. The densitometrical ratios of $\mathrm{p}$-ERKI to t-ERKI of the picture were indicated under the panel.

phosphorylation was dependent of the stimulation of the M1 mAChR by CCh.

\section{Oral administration of CS extracts ameliorates memory impairment caused by scopolamine in CD-I mice}

Administration of anti-cholinergic drugs such as scopolamine, 3-quinuclidinyl benzilate (3-QNB), and ethylcholine aziridium (AF64A) have been reported to induce memory impairment in both rodents and humans by disturbing the function of mAChR. ${ }^{36-38}$ We examined the effect of oral administration of CS extracts (HW + E) on scopolamineinduced amnesia model mice (Figure 3A). Subcutaneous injection of scopolamine significantly decreased spontaneous alternation percentage (SA\%), an index of memory in YM, while oral administration of CS extracts $(\mathrm{HW}+\mathrm{E})$ significantly attenuated scopolamine-induced decrease in SA\% (Figure 3B).

We subsequently performed a passive-avoidance task (PA) to evaluate the effect of CS extracts on contextual memory impairment. In the training session or memory
A

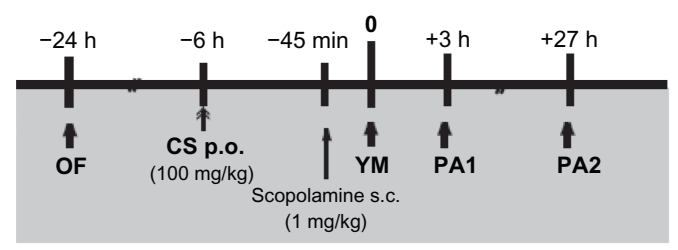

B
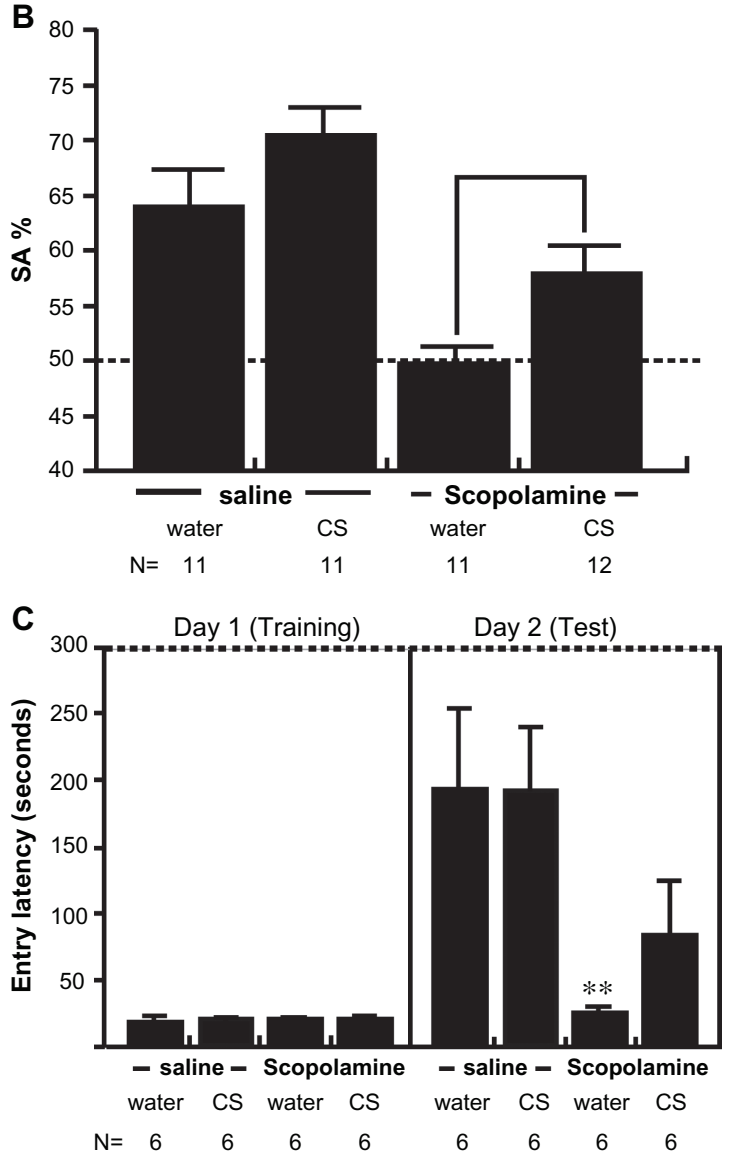

Figure 3 Behavioral analyses of scopolamine-induced amnesia model orally treated with CS extracts. A) A schematic description of the experimental schedule. OF, an open field test; YM, a Y-maze test; PA, a passive avoidance test (PAI represents a training session and PA2 represents a test session). OF, YM, and PA were sequentially performed. We examined the effect of orally (per os or per oral, p.o.)administered CS extracts ( $\mathrm{HW}+\mathrm{E}, 100 \mathrm{mg} / \mathrm{kg}$ ) on memory impairment induced by subcutaneously (s.c.)-injected scopolamine $(1.0 \mathrm{mg} / \mathrm{kg}$ ). The time point when a mouse tested in YM was defined as zero. OF, CS administration, and scopolamine injection were performed 24 hours, 6 hours, and 45 minutes before YM, respectively. PAI was performed 3 hours after YM without additional injection of scopolamine. PA2 was performed 27 hours after YM (24 hours after PAI). B) Results of spontaneous alternation\% (SA\%) in YM of mice treated with CS extracts together with scopolamine. Random choices in YM, which suggest loss of memory, will result in $50 \%$ (indicated as a broken line). Data are shown as means \pm SEM. ANOVA revealed a significant difference $\left(F_{(3,41)}=14.02 ; P<0.0001\right)$. $* P<0.05$ by a Tukey's post hoc test. C) Results of entry latencies in PA. Data are shown as means \pm SEM. One-way ANOVA revealed a significant difference $\left(F_{(3,20)}=3.822 ; P=0.0258\right)$. $* P<0.05$ by a Tukey's post hoc test.

acquisition session (Day 1), there were no differences in the entry latencies among the four treatment groups (Figure 3C, left). In the test session or memory retention trial (Day 2), the entry latencies of the mice receiving s.c. saline injection together with the oral vehicle (water) pretreatment or CS 
extracts were robustly prolonged as compared with those in the training session, suggesting that the mice without scopolamine treatment acquired contextual memory in PA on Day1 and that the memory was retained at least for 24 hours (Figure 3C, right). The entry latency of the mice receiving s.c. scopolamine injection together with the oral vehicle pretreatment in the test session was equivalent to that in the training session, suggesting that scopolamine treatment almost completely inhibited memory acquisition in the training session. Oral pretreatment with CS extract, in clear contrast, significantly prolonged the entry latency of the mice with scopolamine injection, suggesting that CS extracts attenuated scopolamine-induced memory impairment (Figure 3C, right). Thus, CS extract is likely to prevent memory impairment related to the dysfunction of mAChR.

\section{Discussion}

In the present study we aimed to identify natural ingredients promoting M1 mAChR by using an in vitro functional assay system based on ERK phosphorylation induced by $\mathrm{CCh}$. The ERK phosphorylation caused by CCh in F11 cells is deemed to be dependent on M1 mAChR function because the specific M1 mAChR inhibitor completely abolishes, and ectopic overexpression of M1 mAChR augmented, the ERK phosphorylation by $\mathrm{CCh} .{ }^{14}$ Using the in vitro system, we have first found that CS extracts is likely to promote M1 mAChR function in vitro. Using an antimuscarinic drug scopolamine-induced memory impairment model, we further confirmed that CS extracts improve M1 mAChR in vivo as well. This is the first study in which the effects of CS extracts on $\mathrm{M} 1 \mathrm{mAChR}$ are reported.

CS has long been used as a traditional Chinese medicine to ameliorate conditions associated with aging and senescence, such as weakness in the loins and knees, or fatigue. Multiple researches have shown that CS contains crude protein, D-mannitol, cordycepin, ${ }^{39,40}$ and cordyceps polysaccharide ${ }^{41}$ as bioactive constituents. Considering that memory dysfunction is a common symptom of aging, ${ }^{15,42,43}$ the effect of CS extracts on memory through promotion of M1 mAChR may be related to other antiaging effects of CS extracts. The main constituents of ECS are fat-soluble components such as palmitic acid, oleic acid, triglyceride, ergosterol, and cholesterol while those of HWCS are carbohydrate and protein. ${ }^{29}$ Considering that a mixed extract $(\mathrm{HW}+\mathrm{E})$ significantly augmented ERK phosphorylation by $\mathrm{CCh}$, fat-soluble components of $\mathrm{CS}$ and water-soluble components are likely to cooperate in the regulation of M1 $\mathrm{mAChR}$. The active components involved in the CS extracts should be identified in future research.

A number of studies have been aimed at addressing the antioxidant effects of CS extracts. ${ }^{21,22,30,31}$ The ROS scavenging effect of CS extracts may be related to the effect on M1 mAChR because M1 mAChR is reported to determine cellular vulnerability to oxidative stress. ${ }^{44}$ It is, however, also reported that ROS is involved in the regulation of M1 mAChR function as a second messenger. ${ }^{45}$ We have reported that the JAK2/ STAT3 signaling axis sensitizes the function of M1 mAChR. ${ }^{14}$ The activation of the JAK2/STAT3 axis may also be involved in the regulation of M1 mAChR by CS extracts because the JAK2/STAT3 can be activated by some interleukins (ILs) such as IL-6 and CS extracts upregulate ILs including IL-6, at least, in peripheral blood mononuclear cells. ${ }^{46}$ The effect of CS extracts on M1 mAChR phosphorylation and internalization, which is related to the receptor desensitization, should also be addressed. ${ }^{47}$

In conclusion, the in vitro M1 mAChR assay system will serve as a useful tool in a functional screening of novel bioactive components improving M1 mAChR. A mixed extract from $\mathrm{CS}(\mathrm{HW}+\mathrm{E})$ contains such active components. CS extracts may serve as a potential therapy which could be used to treat memory dysfunction related to AD.

\section{Acknowledgment/disclosure}

The authors are grateful to the late Prof Ikuo Nishimoto and also thank Ms T Hiraki and T Yoshida-Nishimoto for indispensable support, and Messrs S Hayashi, A Goto, and K Yamashita for animal husbandry. This work was supported in part by grants from the Fumi Yamamura Memorial Foundation for Female Natural scientists (MY is a Yamamura Fellow), the KEIO Gijuku Academic Development Funds (TC), and Noevir Co. Ltd. KT and MI are employees of Noevir Co. Ltd. Study funders include Noevir Co. Ltd., however, these companies had no role in study design, data collection, or analysis. Author contributions are as follows: TC and MY conceived of and designed the experiments; KT and MI prepared the CS extracts; MY, MS, and JS performed the experiments; TC analyzed the data; TC, MS, JS, and SA wrote the paper.

\section{References}

1. Bartus RT, Dean RL 3rd, Beer B, et al. The Cholinergic hypothesis of geriatric memory dysfunction. Science. 1982;217:408-417.

2. Coyle JT, Price DL, DeLong MR. Alzheimer's Disease: a disorder of cortical cholinergic innervation. Science. 1983;219:1184-1190. 
3. Courtney C, Farrell D, Gray R, et al. Long-term donepezil treatment in 565 patients with Alzheimer's disease (AD2000): randomised doubleblind trial. Lancet. 2004;363:2105-2115.

4. Lane RM, Kivipelto M, Greig NH. Acetylcholinesterase and its inhibition in Alzheimer disease. Clin Neuropharmacol. 2004;27:141-149. Review.

5. Petersen RC, Thomas RG, Grundman M, et al. Vitamin E and donepezil for the treatment of mild cognitive impairment. N Engl J Med. 2005; 352:2379-2388.

6. Winblad B, Kilander L, Eriksson S, et al; Severe Alzheimer's Disease Study Group. Donepezil in patients with severe Alzheimer's disease: double-blind, parallel-group, placebo-controlled study. Lancet. 2006;367:1057-1065.

7. Dani JA. Overview of nicotinic receptors and their roles in the central nervous system. Biol Psychiatry. 2001;49:166-174. Review.

8. Terry AV Jr, Buccafusco JJ. The cholinergic hypothesis of age and Alzheimer's disease-related cognitive deficits: recent challenges and their implications for novel drug development. J Pharmacol Exp Ther. 2003;306:821-827. Review.

9. van Koppen CJ, Kaiser B. Regulation of muscarinic acetylcholine receptor signaling. Pharmacol Ther. 2003;98:197-220. Review.

10. Fisher A. Cholinergic treatments with emphasis on $\mathrm{m} 1$ muscarinic agonists as potential disease-modifying agents for Alzheimer's disease Neurotherapeutics. 2008;5:433-442. Review.

11. Sur C, Mallorga PJ, Wittmann M, et al. N-desmethylclozapine, an allosteric agonist at muscarinic 1 receptor, potentiates N-methylD-aspartate receptor activity. Proc Natl Acad Sci U S A. 2003;100: 13674-13679.

12. Anagnostaras SG, Murphy GG, Hamilton SE, et al. Selective cognitive dysfunction in acetylcholine M1 muscarinic receptor mutant mice. Nat Neurosci. 2003;6:51-58.

13. Caccamo A, Oddo S, Billings LM, et al. M1 receptors play a central role in modulating AD-like pathology in transgenic mice. Neuron. 2006;49:671-682.

14. Chiba T, Yamada M, Sasabe J, et al. Amyloid-beta causes memory impairment by disturbing the JAK2/STAT3 axis in hippocampal neurons. Mol Psychiatry. 2009;14:206-222.

15. Chiba T, Yamada M, Aiso S. Targeting the JAK2/STAT3 axis in Alzheimer's disease. Expert Opin Ther Targets. 2009;13:1155-1167. Review.

16. Scheiderer CL, Smith CC, McCutchen E, et al. Coactivation of M(1) muscarinic and alpha1 adrenergic receptors stimulates extracellular signal-regulated protein kinase and induces long-term depression at CA3-CA1 synapses in rat hippocampus. $J$ Neurosci. 2008;28: $5350-5358$.

17. VanDeMark KL, Guizzetti M, Giordano G, et al. The activation of M1 muscarinic receptor signaling induces neuronal differentiation in pyramidal hippocampal neurons. J Pharmacol Exp Ther. 2009; 329:532-542.

18. Berkeley JL, Levey AI. Muscarinic activation of mitogen-activated protein kinase in PC12 cells. $J$ Neurochem. 2000;75:487-493.

19. Bok JW, Lermer L, Chilton J, et al. Antitumor sterols from the mycelia of Cordyceps sinensis. Phytochemistry. 1999;51:891-898.

20. Lee H, Kim YJ, Kim HW, et al. Induction of apoptosis by Cordyceps militaris through activation of caspase- 3 in leukemia HL-60 cells. Biol Pharm Bull. 2006;29:670-674.

21. Li SP, Zhao KJ, Ji ZN, et al. A polysaccharide isolated from Cordyceps sinensis, a traditional Chinese medicine, protects PC12 cells against hydrogen peroxide-induced injury. Life Sci. 2003;73: 2503-2513.

22. Yamaguchi Y, Kagota S, Nakamura K, et al. Antioxidant activity of the extracts from fruiting bodies of cultured Cordyceps sinensis. Phytother Res. 2000;14:647-649.

23. Kuo YC, Tsai WJ, Wang JY, et al. Regulation of bronchoalveolar lavage fluids cell function by the immunomodulatory agents from Cordyceps sinensis. Life Sci. 2001;68:1067-1082.
24. Koh JH, Yu KW, Suh HJ, et al. Activation of macrophages and the intestinal immune system by an orally administered decoction from cultured mycelia of Cordyceps sinensis. Biosci Biotechnol Biochem. 2002;66:407-411.

25. Wu Y, Sun H, Qin F, Pan Y, et al. Effect of various extracts and a polysaccharide from the edible mycelia of Cordyceps sinensis on cellular and humoral immune response against ovalbumin in mice. Phytother Res. 2006;20:646-652.

26. Zhang G, Huang Y, Bian Y, et al. Hypoglycemic activity of the fungi Cordyceps militaris, Cordyceps sinensis, Tricholoma mongolicum, and Omphalia lapidescens in streptozotocin-induced diabetic rats. Appl Microbiol Biotechnol. 2006;72:1152-1156.

27. Balon TW, Jasman AP, Zhu JS. A fermentation product of Cordyceps sinensis increases whole-body insulin sensitivity in rats. J Altern Complement Med. 2002;8:315-323.

28. Chiou WF, Chang PC, Chou CJ, et al. Protein constituent contributes to the hypotensive and vasorelaxant activities of Cordyceps sinensis. Life Sci. 2000;66:1369-1376.

29. Nishizawa K, Torii K, Kawasaki A, et al. Antidepressant-like effect of Cordyceps sinensis in the mouse tail suspension test. Biol Pharm Bull. 2007;30:1758-1762.

30. Jin DQ, Park BC, Lee JS, et al. Mycelial extract of Cordyceps ophioglossoides prevents neuronal cell death and ameliorates betaamyloid peptide-induced memory deficits in rats. Biol Pharm Bull. 2004;27:1126-1129.

31. Ji DB, Ye J, Li CL, et al. Antiaging effect of Cordyceps sinensis extract. Phytother Res. 2009;23:116-122.

32. Chiba T, Yamada M, Hashimoto Y, et al. Development of a femtomolaracting humanin derivative named colivelin by attaching activitydependent neurotrophic factor to its $\mathrm{N}$ terminus: characterization of colivelin-mediated neuroprotection against Alzheimer's disease-relevant insults in vitro and in vivo. $J$ Neurosci. 2005;25: 10252-10261

33. Yamada M, Chiba T, Sasabe J, et al. Implanted cannula-mediated repetitive administration of Abeta25-35 into the mouse cerebral ventricle effectively impairs spatial working memory. Behav Brain Res. 2005;164:139-146.

34. Yamada M, Chiba T, Sasabe J, et al. Nasal Colivelin treatment ameliorates memory impairment related to Alzheimer's disease. Neuropsychopharmacology. 2008;33:2020-2032.

35. Hudkins RL, DeHaven-Hudkins DL. M1 muscarinic antagonists interact with sigma recognition sites. Life Sci. 1991;49:1229-1235. Erratum in: Life Sci. 1992;50:245.

36. Fisher A, Brandeis R, Pittel Z, et al. (+)-cis-2-Methyl-spiro(1,3oxathiolane-5, $3^{\prime}$ ) quinuclidine (AF102B): a new M1 agonist attenuates cognitive dysfunctions in AF64A-treated rats. Neurosci Lett. 1989;102:325-331.

37. Mamiya T, Ukai M. [Gly(14)]-humanin improved the learning and memory impairment induced by scopolamine in vivo. Br J Pharmacol. 2001;134:1597-1599.

38. Krejcova G, Patocka J, Slaninova J. Effect of humanin analogues on experimentally induced impairment of spatial memory in rats. $J$ Pept Sci. 2004;10:636-639.

39. Cunningham KG, Manson W, Spring FS, et al. Cordycepin, a metabolic product isolated from cultures of Cordyceps militaris (Linn.) Link. Nature. 1950;166:949.

40. Kredich NM, Guarino AJ. An improved method of isolation and determination of cordycepin. Biochim Biophys Acta. 1960;41: 363-365.

41. Yamada H, Kawaguchi N, Ohmori T, et al. Structure and antitumor activity of an alkali-soluble polysaccharide from Cordyceps ophioglossoides. Carbohydr Res. 1984;125:107-115.

42. Lister JP, Barnes CA. Neurobiological changes in the hippocampus during normative aging. Arch Neurol. 2009;66:829-833.

43. Chiba T, Nishimoto I, Aiso S, et al. Neuroprotection against neurodegenerative diseases. Mol Neurobiol. 2007;35:55-84. 
44. Joseph JA, Fisher DR, Strain J. Muscarinic receptor subtype determines vulnerability to oxidative stress in COS-7 cells. Free Radic Biol Med. 2002;32:153-161.

45. Mangelus M, Kroyter A, Galron R, et al. Reactive oxygen species regulate signaling pathways induced by $\mathrm{M} 1$ muscarinic receptors in PC12M1 cells. J Neurochem. 2001;76:1701-1711.

46. Zhou X, Luo L, Dressel W, et al. Cordycepin is an immunoregulatory active ingredient of Cordyceps sinensis. Am J Chin Med. 2008;36:967-980.
47. Mundell SJ, Pula G, McIlhinney RA, et al. Desensitization and internalization of metabotropic glutamate receptor 1a following activation of heterologous Gq/11-coupled receptors. Biochemistry. 2004;43:7541-7551.

\section{Publish your work in this journal}

The Journal of Receptor, Ligand and Channel Research is an international, peer-reviewed, open access, online journal. The journal welcomes laboratory and clinical findings in the fields of biological receptors, ligands, channel and signal transduction research including: receptors and signalling; ligands; transporters, pores and channels; binding and activation; receptor regulation; role of receptors in diseases and their treatment; molecular basis of membrane structure and functions; molecular models of membranes. The manuscript management system is completely online and includes a very quick and fair peer-review system. Visit http://www.dovepress.com/ testimonials.php to read real quotes from published authors.

Submit your manuscript here: http://www.dovepress.com/journal-of-receptor-ligand-and-channel-research-journal 